\title{
El arquitecto Jaime Bort en París (1751-1752)
}

\section{The architect Jaime Bort in Paris (1751-1752)}

\author{
MARINA FORTE CUTILLAS \\ Universidad Complutense de Madrid \\ marina-forte@hotmail.com
}

Resumen: Tras haber sido aceptado en la Corte, el arquitecto Jaime Bort emprende un periplo europeo promovido por el marqués de la Ensenada y el marqués de Rafal. Bajo un nuevo intento de modernizar la ciudad de Madrid y rescatarla del precario estado higiénico en que se hallaba, Bort debería estudiar las soluciones que otras capitales hubieran adoptado. En su correspondencia desde París, aquí transcrita, puede estudiarse cuál fue su actividad durante su viaje europeo, en absoluto reducida a estudiar las posibles soluciones para mejorar la limpieza de Madrid.

Palabras clave: Jaime Bort, viaje por Europa, París, marqués de la Ensenada, Pedro Franco Dávila.

\begin{abstract}
After being accepted in the Court, the architect Jaime Bort starts a new European trip persuaded by Marquis de la Ensenada and Marquis de Rafal. Under a new attempt to make the city of Madrid modern and save it from the filthy hygiene state, Bort needs to look into solutions that other metropolis had taken.. In his correspondence from Paris, which is transcribed here, it can be found which activity Bort was doing during his European trip, not only limited to study the solutions carried out to improve the cleaning stage of Madrid.
\end{abstract}

Keywords: Jaime Bort, European trip, Paris, marqués de la Ensenada, Pedro Franco Dávila.

Recibido: 4 de julio de 2017; aceptado: 11 de noviembre de 2017; publicado: 27 de marzo de 2018. Revista Historia Autónoma, 12 (2018), pp. 121-132. 
Invierno de 1736: el arquitecto Jaime Bort se traslada a la ciudad de Murcia. Ya ha sido maestro mayor de la catedral de Cuenca y, sin saberlo, va dando los primeros pasos para su posterior traslado a la corte madrileña. También para el viaje europeo que el marqués de la Ensenada, ministro preocupado por hallar soluciones al problema higiénico y de renovación urbanística de la capital, le encomendaría años después. Invierno de 1751: Bort emprende el periplo europeo del que nunca vería los frutos - por razones que ya expuso la profesora Beatriz Blasco y que volveré a citar más adelante_-1, pero no por ello se le ha de restar importancia. Cometeríamos el error de olvidar el inquieto espíritu de esta misión y la red, bien asentada en la corte, que la promovió y dirigió.

Antes de lanzarse a tierras extranjeras, Bort contaba con un largo historial de obras como arquitecto e ingeniero. Nacido en 1693 en Coves de Vinroma (Castellón) ${ }^{2}$, haría de las ciudades de Cuenca, Murcia y alrededores, escenarios de sus proyectos y actuaciones. En el año 1748 se instaló en Madrid, pues Antonio de Heredia y Bazán, marqués de Rafal, que había sido nombrado corregidor de la ciudad un año antes, lo instó a realizar algunas obras nuevas para la capital del país. Que el marqués ocupara el mismo cargo en Murcia convirtió a Bort en el arquitecto de su confianza. No es de extrañar, pues todavía perdura su indudable valía: el imafronte de la catedral murciana se yergue como su más reconocido símbolo, y el Puente Viejo o la Contraparada mantienen aún hoy su función ${ }^{3}$. Su prestigio fue tal que lo llevó a actuar también en localidades vecinas como en la Fuente del Oro en Lorca ${ }^{4}$, el ayuntamiento de Caravaca o a participar en Santa Justa de Orihuela 5 .

El momento de mayor reconocimiento se acercaba cuando, en noviembre de 1748, el marqués de la Ensenada, máximo responsable de los asuntos de Hacienda, Guerra, Marina e Indias $^{6}$, le encargó los diseños del puente de San Fernando y el de Trofa ${ }^{7}$. En 1749 fue aprobado

\footnotetext{
${ }^{1}$ Se analiza con detalle en Blasco Esquivias, Beatriz, iAgua va! La higiene urbana de Madrid (1561-1761), Madrid, Caja de Madrid, 1998.

${ }^{2}$ Arroyas Serrano, Magín, "Legado natal en la testamentaria: Jaime Bort, un arquitecto nacido en Coves de Vinroma (Castellón)", en Verdolay, 8 (1996), pp. 111-115.

${ }^{3}$ De la Ossa Giménez, Elena, "El puente de piedra de Murcia. Los ingenieros que lo trazaron y ejecutaron", en Bores, Fernando et al. (eds.), Actas del II Congreso Nacional de Historia de la Construcción, Santiago de Compostela, Universidad de La Coruña, 1998, pp. 125-130; de la Peña Velasco, Concepción, El puente viejo de Murcia, Murcia, Universidad de Murcia, 2001.

${ }^{4}$ Pelegrín Garrido, Mariano, "Presa subálvea de la Fuente del oro en Lorca", en Alberca, 3 (2005), pp. 5-10.

${ }^{5}$ El trabajo de referencia para la obra de Jaime Bort en Murcia corresponde a: Hernández Albadalejo, Elías, "Jaime Bort: un arquitecto barroco", en Hernández Albadalejo, Elías, La fachada de la catedral de Murcia, Murcia, Asamblea Regional de Murcia, 1990, pp. 387-420. De gran interés son también las noticias reunidas en Belda Navarro, Cristóbal y Elías Hernández Albadalejo, Arte en la región de Murcia. De su Reconquista a la Ilustración, Murcia, Comunidad Autónoma de la Región de Murcia, 2006.

${ }^{6}$ Gómez Urdáñez, José Luis, "El proyecto político ensenadista en la polémica sobre el despotismo ilustrado en España. Notas sobre el proyecto de investigación Ensenada 2002”, en Brocar, 19 (1995), pp. 85-130; Ozanan, Didier, "El marqués de la Ensenada", en Fernando VI y Bárbara de Braganza; un reinado bajo el signo de la paz, Madrid, Ministerio de Educación, Cultura y Deporte, 2002, p. 300; Gómez Urdáñez, José Luis, El marqués de Ensenada, el secretario de todo, Madrid, Punto de Vista, 2017.

${ }^{7}$ Tarraga, María Luisa, "Los hermanos Jaime y Vicente Bort en la Corte: el Puente Verde y el de Trofa", en Imafronte, 2 (1986), pp. 65-82; Corella Suárez, Pilar, "El puente verde o de San Fernando sobre el Manzanares en el camino de El Pardo", en Villa de Madrid, 96 (1988), pp. 55-68.
} 
un proyecto suyo para un paseo entre la Puerta de Atocha y el río Manzanares ${ }^{8}$. Con estas últimas intervenciones logró satisfacer a los reyes y ganar la consideración que lo convertiría en candidato para afrontar el saneamiento urbano de Madrid, problema que ya venía acuciando a la monarquía desde Felipe V. En 1715, se intentó la implantación definitiva de un régimen de limpieza con las propuestas de Teodoro Ardemans y José Alonso de Arce, además de introducir un Reglamento para la limpieza y el empedrado de Madrid 9 . Fueron las únicas intervenciones que no quedaron en el plano teórico hasta dos reinados después, ya bajo Carlos III. Mientras tanto, la capital se mantuvo sumida en el descuido, como bien escribió cruda y detalladamente, el marqués de Uztáriz en 1746. Este último mostró el precario estado higiénico de la ciudad, el poco efecto que habían tenido las medidas anteriores, afirmando incluso que "no solamente es Madrid la Corte más sucia que se conoce en Europa, sino la villa más desatendida en este punto de cuantas tiene nuestro Rey en sus dominios"10.

Tomando como ejemplo el viaje que había realizado el ingeniero marino Antonio de Ulloa entre 1749 y comienzos de $1752^{11}$ proponiendo ciertas capitales del continente como modelos adecuados en su informe Limpieza de París, método que se observa para ello; y el que parece más proporcionado que pudiera aplicarse a Madrid, en 1751 Ensenada y Heredia encargaron a Jaime Bort un viaje a ciudades europeas para reunir y estudiar ideas y medidas que poder implantar cuanto antes en España. Así es como con dos futuros reconocidos arquitectos, su sobrino Julián Sánchez Bort y José de Castañeda, marchan, en el invierno de 1751, junto a Jaime para instruirse "en el manejo y conducta de todo género de obras, nominadamente las de agua", como el mismo Sánchez Bort expresaría ${ }^{12}$. El estudio de puentes, red de alcantarillado, canales y — sobre todo- planes de limpieza, conformó la misión central de estos viajeros. No obstante, no desaprovecharon la oportunidad para recoger y transmitir a sus poderosos protectores nociones sobre decoración de interiores, coleccionismo, arquitectura y hasta sus propias impresiones sobre algunos personajes de interés que conocieron, entre ellos Pedro Franco Dávila.

\footnotetext{
${ }^{8}$ Crespo Delgado, Daniel, "Una época para el cambio. Los viajes del arquitecto e ingeniero Julián Sánchez Bort”, en Cámara Muñoz, Alicia y Bernardo Revuelta Pol (coords.), Libros, caminos y días. El viaje del ingeniero, Madrid, Fundación Juanelo Turriano, 2016, p. 81.

${ }^{9}$ Blasco Esquivias, Beatriz, "La santéurbaine à Madrid. Le projet de Jaime Bort pourl'évacuation des eauxusées" en Dix-huitièmeSiècle, 22 (1990), pp. 255-267. DOI: https://doi.org/10.3406/dhs.1990.1759.

${ }^{10}$ Discurso sobre el gobierno de Madrid, lo importante de su exerzion las ventajas que se pueden producir con utilidad del Real Servicio y del Público, citado en Blasco Esquivias, Beatriz, "Tradición y reforma en el Madrid de Fernando VI: la policía urbana y el progreso de la ciudad", en Fernando VI y Bárbara de Braganza ... op. cit., p. 61. ${ }^{11}$ Helguera Quijada, Juan, "La introducción de nuevas técnicas: de la inmigración tecnológica al espionaje industrial”, en Silva Suárez, Manuel (coord.), Técnica e ingeniería en España III. El Siglo de las Luces, Zaragoza, Institución Fernando el Católico, Prensas Universitarias de Zaragoza y Real Academia de Ingeniería, 2005, pp. 58-71.

${ }^{12}$ Lo escribió en un informe firmado en agosto de 1752 y presentado a la Academia de San Fernando. Archivo de la Real Academia de Bellas Artes de San Fernando, leg.5-126-2. Aparece transcrito en Rodríguez-Villasante Prieto, Juan Antonio, La obra de Julián Sánchez Bort en el conjunto histórico de Ferrol y su referencia al mundo académico, Ferrol, Concello de Ferrol, 2004.
} 
Bort dio noticia del naturalista en la última de las tres cartas que conservamos, fechada en febrero de $1752^{13}$, y que aquí transcribimos. De hecho, en el mismo legajo se conserva una copia de la correspondencia que mantendrían en julio del mismo año, cuando ya el arquitecto se encontraba de nuevo en Madrid ${ }^{14}$. En ella Dávila se lamenta por no haber conocido a Ensenada, pero informa a Bort sobre unos bustos de bronce que podrían servir para la casa de campo que el marqués pensaba construirse. También le relata la compra de una colección de minerales, la cual considera incluso mejor que la del rey, una de "primeras piedras" y otra de conchas, con la que "no hay persona que pueda disputarme la perfección en esta parte de la Historia Natural"15. Muestra además sus importantes contactos entre parte de la aristocracia y la élite parisina, desvelándose el destacado ambiente cultural con el que Dávila —y también Bort— se relacionaron.

De las cartas que Bort enviaba relatando todo lo que les acontecía se conservan tres, como ya apuntamos, con destinatarios y contenidos diferentes. La primera de ellas, dirigida al marqués de Rafal, data del 20 de diciembre de 1751 y testifica un viaje duro y lleno de obstáculos: los tres viajeros caen enfermos, el frío intenso y poco ofrecimiento por parte de los franceses, junto con el escaso capital del que disponían, merecieron la queja de Bort. Seis días después escribe a Agustín Pablo de Ordeñana, mano derecha de Ensenada, que había sido nombrado desde abril Secretario de Estado y Guerra ${ }^{16}$. Ordeñana tenía sólidas inquietudes culturales y una de las bibliotecas más ricas de todo el país ${ }^{17}$. La posibilidad de que Bort conociera o compartiera libros de Carlo Fontana, Palladio o Scamozzi con Martín Solera durante su estancia en Murcia ${ }^{18}$, evidencia que no le fue ajena la cultura libresca ni tampoco ciertos códigos y elementos de sociabilidad que le permitirían participar de las redes de poder e influencia. En todo caso, es en esta misiva donde expone al más crítico y ambicioso ingeniero tomando nota de la arquitectura y del gusto parisino así como de la iluminación de las calles y las casas. Concede especial interés al sistema de evacuación de aguas residuales y a los puentes, ya que "exceden a los

\footnotetext{
${ }^{13}$ Bort pasa a ser uno de los lazos de Dávila con la corte española. No obstante, no sería el único. Destaca la figura de Manuel de Junco y Pimentel, cuya correspondencia con el guayaquileño comienza el 5 de diciembre de 1752 , momento en el que Jaime Bort se encontraba ya hacía casi un año en la capital francesa. Podemos asegurar que Bort conocía a Dávila desde diez meses atrás. En lo referente a Pedro Franco Dávila y su contacto con España: Villena Sánchez-Valero, Miguel, "Dávila y la ilustración española" en Villena Sánchez-Valero, Miguel et al., El gabinete perdido. Pedro Franco Dávila y la Historia Natural del Siglo de las Luces, Madrid, Consejo Superior de Investigaciones Científicas, 2009, pp. 203-237; Sánchez Almazán, Javier, "Relaciones de Pedro Franco Dávila con el mundo ilustrado español antes de su venida a España”, en Sánchez Almazán, Javier, Pedro Franco Dávila (17111786). De Guayaquil a la Royal Society. La época y la obra de un ilustrado criollo, Madrid, Consejo Superior de Investigaciones Científicas, 2012, pp. 122-137; Calatayud Arinero, María Ángeles, Catálogo de documentos del Real Gabinete de Historia Natural (1752-1786), Madrid, Consejo de Investigaciones científicas, 1987, p. 11. ${ }_{14}^{14}$ Archivo General de Simancas [en adelante, AGS], Gracia y Justicia, leg. 998.

${ }^{15}$ Sobre la formación de la colección de Dávila, así como la del Real Gabinete de Historia Natural, ver Sánchez Almazán, Javier, "La creación del Real Gabinete de Historia Natural” y "El Real Gabinete y su impulso a la ciencia en España", en Una colección, un criollo erudito, y un rey. Un gabinete para la monarquía ilustrada, catálogo de la exposición (Madrid, Museo Nacional de Ciencias Naturales, 2016). Madrid, Editorial CSIC, pp. 13-77.

${ }^{16}$ Escudero, José Antonio, Los orígenes del Consejo de Ministros en España, Madrid, Editorial Complutense, 2001, p. 227.

${ }^{17}$ González Caizán, Cristina, “Agustín Pablo de Ordeñana (Bilbao, 1711-Madrid, 1765): un ilustrado en la corte Fernando VI", en Bidebarrieta, 17 (2006), pp. 487-505.

${ }^{18}$ De la Peña Velasco, Concepción, "La biblioteca de Martín Solera, un maestro de obras del siglo XVIII en Murcia”, en Imafronte, 1 (1985), pp. 73-86.
} 
romanos según veo en las ponderaciones de aquellos y las obras de estos". Le causa admiración la perseverancia de los trabajadores y las rigurosas medidas con las que mantienen en tan buenas condiciones la ciudad, algo que subraya como desconocido en España.

La última epístola, dirigida a Ensenada y ya de febrero de 1752, es la más larga y la prueba de que procurase que el viaje fuera enriquecedor en todos los ámbitos posibles y no se limitase meramente a recabar información técnica. Le describe el carácter de Dávila y las actividades que realizaba en París pretendiendo - creemos - incluirlo en la trama de hombres de confianza del ministro. Relata un día a día de Dávila inmerso en el debate por el gusto y el coleccionismo, por los que mostraba verdadera pasión: "este hombre prefiere el gusto a cuantos tesoros pudiera lograr [...] y creo despreciará cuanto el mundo ofrece de intereses con tal de no privarse de su inclinación". Le comunica al ministro las ganas del naturalista de que conozca parte de su colección. Incluso le hace una petición en favor del guayaquileño proponiendo que "tuviera gran gusto que Vuestra Excelencia le mandara algo porque tiene grandes noticias del gusto y grandiosidad de Vuestra Excelencia".

Según parece, Bort no había pisado todavía tierras flamencas, ya que se refiere a ellas como futuro destino señalado por Ulloa, quien le indica que elabore un exhaustivo estudio de los diques, canales y molinos que allí encuentre, pues "me aseguran que para esto son los únicos". Partiría hacia ellas una vez hubiera realizado los modelos de tres molinos, una cisterna y de la máquina de La Samaritaine, ingenio ubicado en el pont Neuf para elevar agua del Sena y que de seguro causaría especial fascinación en nuestro arquitecto. Demostrando el papel director que Ensenada cumplía en esta misión, vemos cómo Bort le pide su aprobación en el rumbo que tomar a la vuelta — por el cual visitaría el celebérrimo canal de Languedoc-. Asimismo, le pide permiso para seguir en compañía de su sobrino, alabando su ayuda y enorme capacidad. A Sánchez Bort le llegaría el reconocimiento años más tarde, sumándose a proyectos tan importantes como el arsenal de Ferrol o el canal de Aragón, del cual fue nombrado director en $1775^{19}$. Finaliza la carta y la correspondencia que conservamos halagando la educación y refinamiento francés antes de lamentarse por el mal procedimiento de pago y la metodología de trabajo española.

Con la llegada de Bort a Madrid en el verano de 1752, comenzó la tarea crucial: la realización de un informe que dictara los futuros procedimientos a seguir y la solución que rescatase a la capital española del atraso, para elevarla al mismo nivel que los modelos europeos —el parisino en especial—. Su propuesta contaba con 136 folios explicativos de su veredicto final, acomodando las ideas extraídas a las singularidades madrileñas ${ }^{20}$. El medio para solucionar

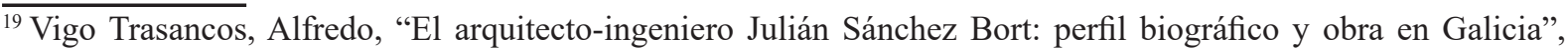
en Cuadernos de Estudios Gallegos, 100 (1984-1985), pp. 501-525; Sambricio, Carlos, Territorio y ciudad en la España de la Ilustración, Madrid, Ministerio de Obras Públicas y Transporte, 1991; Rodríguez Ruiz, Delfín, "Arquitectura y academia durante el reinado de Fernando VI", en Fernando VI y Bárbara ... op. cit., pp. 219-243. Crespo Delgado, Daniel, Libros, caminos y días ... op. cit., p. 84.

${ }^{20}$ Blasco Esquivias, Beatriz, “Tradición y reforma...” op. cit., , pp. 68-71.
} 
el problema higiénico sería la instalación de pozos negros en las viviendas, para extinguir al fin los gritos que pregonaban, descaradamente, el retraso en el que se hallaba sumida la ciudad. Poner fin al “'Agua va!” y dejar que lo que viniera fueran las reformas ilustradas.

Tal propósito quedó como uno más de los intentos fallidos, al verse truncado por la conjura contra Ensenada y su posterior destierro, la crisis económica y el fallecimiento de Jaime Bort en 1754 , apenas dos años después de su regreso ${ }^{21}$. Pero, si algo es cierto, es que la importancia del proyecto no radica únicamente en si se llevó a cabo o no a su vuelta a España, sino en todo aquello ligado al viaje. El hecho de que, movidos por el anhelo de cambio, se buscase la inspiración más allá de las fronteras del país, que a su luz se quisieran descubrir y trazar los caminos que propiciasen una necesaria renovación de la que Bort pretendió ser la mirada y la tinta.

\section{Anexo 1: Carta de Jaime Bort a Antonio de Heredia y Bazán, marqués de Rafal, 20 de diciembre de $1751^{22}$.}

París, 20 diciembre de 1751

Recibí la de Vuestra Señoría del 6 de diciembre en que he recibido el mayor gusto por saber se mantiene Vuestra Señoría con salud, mi señora la marquesa y señoritos. Yo me hallo muy mejorado, aunque todavía estoy tomando cada mañana mi papelito de quina por consejo del médico, porque dice que aquí se hacen eternas las cuartanas. Mi sobrino ${ }^{23}$ y Castañeda ${ }^{24}$ todavía andan tropezando, de modo que ya soy yo el más fuerte. El tiempo es tan crudo que no es ponderable, que para endebles se puede temer.

Yo voy registrando cosas y sitios, aunque con mucha pena por la dicha intemperie, lo peor no es sino que hacia Flandes es más frío, con que no debo de hallarme embarazado para la resolución de marchar. Para mis encargos primitivos ya he dicho en mis antecedentes con la lentitud que han andado conmigo porque persona alguna no me han dado. Yo tengo que hacer mis registros y valerme de mozos como Dios me ayuda, pero esto no se puede hacer sin gastar tiempo porque no dándole a una persona inteligente que prontamente despachara, yo ando con miedo, porque conozco andan recelosos con los españoles, porque dicen no han visto jamás otros tantos; ello, lleven españoles lo que era menester para escudriñar a fondo tanto como hay que aprender, criar muchachos de conocido espíritu enseñándoles la lengua francesa, que pudiesen venir sin que fuesen conocidos y tal cual que supiesen algo de matemáticas y con otros pretextos examinar bien tanto como hacen de admirable. Pero así es poco lo que se puede hacer porque le conocen por la pinta.

\footnotetext{
${ }^{21}$ Blasco Esquivias, Beatriz, ;Agua va!... op. cit.

${ }^{22}$ AGS, Gracia y Justicia, leg. 998.

${ }^{23}$ Julián Sánchez Bort.

${ }^{24}$ José de Castañeda.
} 
En una fábrica estuve donde según me dijeron estaban moldando para bronces. Cosa tan útil que no es decible. No me dejaron entrar, sólo al vuelo pude ver algunas piezas. En la misma casa había otras oficinas que me dejaron entrar, pero no pude conocer para qué servían una multitud de máquinas y me salí en ayunas. Es dificilísimo poder examinar en corto tiempo mucho, y es tanto lo que hay que se vuelve uno loco. Un molino de viento hecho de madera que me quedé atónito. Con el primer motor muelen, suben y bajan los costales y ciernen al mismo tiempo. Se sacará modelo lo mejor que se pueda, pero Vuestra Señoría ha de estar en que el tiempo ni el dinero no pueden suplir porque todo cuesta un sentido y nada se puede ver sin pagar.

El pan y todo lo comestible no tiene ponderación: una libra de sal 19 cuartos, el aceite a 30 cuartos la libra, el pan a 7 cuartos la libra, la carne a 2 reales, el vino a 8 reales la azumbre, las pasas a 28 cuartos la libra, y una peluca me ha costado 3 doblones y así de lo demás. Vuestra Señoría piense en que estamos como estaban los israelitas en poder del faraón y no tenemos otro Moisés que Vuestra Señoría, que allí tiene la vara [ilegible] que a Su Excelencia ${ }^{25}$ y al Sr. Ordeñana, y dejando aparte estas verdades evangélicas paso a decir que, aunque costoso, no es difícil el limpiar a Madrid como se hagan obedecer las órdenes del rey como aquí se hacen. Acá no hay vuelos y son un poco más soberbios que los españoles según veo, pero el Rey manda, ya lo ha visto, y al Sr. Delfín y demás recámara no gasta oro ni plata, su manguito grande y su ropón, etc...

Punto al encargo de los tapices pintados al fresco, sobre casi siendo de historia y teniendo 4 varas de alto, cuesta la vara 50 reales; del mismo género, teniendo tan sólo tres varas de alto, cuesta [ilegible] reales. Si es de países, los primeros cuestan a 40 la vara y los segundos a 30 . El Señor Ordeñana tiene en su casa tapices pintados muy ricos y sabe también a cómo valen -esta es la razón-. Hoy me han entregado otros papeles el Sr. Aldecoa, los remitiré por correo. A los señoritos y mi señora la marquesa mil expresiones, he sentido la muerte de Ignacio que ya había aquí dado lo mismo o más. Sentiré que a [ilegible] sepa(?) gobernar. Ahí remito un papel sobre una fábrica de hierro, trabajado a martillo todo género de trastos de cocina. Besa su mano su más atento y seguro servidor,

Jaime Bort.

Sr. Marqués de Rafal.

${ }^{25}$ Ensenada. 
Anexo 2: Carta de Jaime Bort a Agustín Pablo de Ordeñana, 26 de diciembre de 1751 ${ }^{26}$.

Señor, recibí la de Vuestra Señoría de 13 de diciembre con el gusto que Vuestra Señoría puede considerar. Ya gracias a Dios me hallo mejor, aunque todavía tomo mi quina en papelito cada día. Los compañeros, mi sobrino ha estado bastante malo y lo está. Castañeda está con cuartanas actualmente. Al estado presente soy el más fuerte (aunque viejo).

Quedo enterado de los encargos que Vuestra Señoría me hace y pondré todo el cuidado posible, pero es difícil poderlo hacer con mucha brevedad; lo primero por el tiempo que hace que estamos inservibles, y lo otro por no tener conductor, pues hasta la hora de esta no me lo han dado por los recelos que tienen. Yo voy adquiriendo como Dios me ayuda algunos conocimientos y entrándome en las casas nuevas o que están haciéndose y inquiriendo las noticias que puedo, y haré un cómputo de unas y otras, como se componen, así del gasto como del tiempo y vecinos por lo que mira en asunto de limpieza, y lo mismo haré en asunto de los demás.

Al Señor Marqués de Rafal voy enviando las relaciones que puedo adquirir, para luego juntarlo todo el modo con que se alumbra París o ilumina, las leyes y todas las circunstancias. Remito este correo aunque me aseguran se envió este proyecto o disposición, pero por si acaso se ha traspapelado lo remito y con esa noticia veo lo que hacen y su efecto.

Lo cierto es que admira de ver la igualdad, perseverancia y rectitud que se guarda en todo. Acá no hay parvedad de materia, todo el mundo anda listo, es infalible las horas señaladas, llueva o nieve, que deben barrer las calles todas sin exceptuar, aun las más estrechas y desviadas, de modo que llueva o que nieve marcha uno por las calles sin ensuciarse más que el grueso de la suela del zapato, y no obstante eso, en cada esquina hay quien limpia los zapatos por dos liartes $^{27}$ y le exigen y ruegan.

Es de admirar y para pasmarse ver en muchísimas calles alcantarillas o egout ${ }^{28}$ arrimadas a las paredes, de mucha capacidad, construidas de sillería hasta encontrar con el principal egout, el que según juzgo tiene de longitud desde su principio hasta entrar en la ciénaga y cerca de dos leguas todas las traviesas que a él concurren. Cuánto compondrán que de puentes en fin creo exceden a los romanos, según veo las ponderaciones de aquellos y las obras de estos. Y ver nuestro desdichado Prado viejo que asqueroso y desgreñado está que si estuviera en la más corta aldea estuviera mejor.

Para que se vea lo curiosos que son, en la temporada que alumbran los faroles, que es todo el año excepto cuando hay luna, los limpian siete veces. Estas particularidades y otras se podrán ver en el proyecto remitido. Hoy parte Don Antonio Ulloa para Madrid. Me ha informado de lo que hay especial en Bruselas y sus rededores, y aunque le he dicho lo que Vuestra Señoría dice,

\footnotetext{
${ }^{26}$ AGS, Gracia y Justicia, leg. 998.

${ }^{27}$ El liard era una moneda francesa de bajo valor en circulación desde el siglo XV.

${ }^{28}$ Alcantarilla en francés.
} 
me dice que hay mucho especial que ver que se aventaja a París. Me dio una carta y un aderezo o notación de las partes que hay que notar en las ciudades de Flandes y de Francia. Los canales, puentes y máquinas es lo sustancial y donde se tienen los intereses y comodidades y cada día emprenden de nuevos, pero entre los que se ponderan es el de Languedoc, que es el situado en el terreno más irregular. Si a Vuestra Señoría le parece me volveré por esa ruta de Lyon, Marsella y su dirección por esta otra.

Ya he visto lo que hay en Orleans. Están haciendo un puente magnífico. Vi su modo de obrar, que me alegré. En Burdeos no vi el Archivo, pero están haciendo las mayores obras que se pueden imaginar. La gran fábrica de la Bolsa, donde concurren los extranjeros y gente de trato, donde se tiene por octubre que es imponderable su concurso, y más su magnificencia. La plaza tiene 300 pies y sus alas cada una 120 y sus retornos se pierden de vista, el adorno exterior no cede a los edificios de París. Su arquitectura [es] la más selecta que se ha visto; será el archivo en comparación de esta cosa poca.

Y para no cansar a Vuestra Señoría solo digo que en asunto de limpieza se puede hacer lo mismo que en París, y mejor por tener más corrientes las aguas por razón de su terreno, porque si en Madrid hay cuevas acá las hay también; si están las casas juntas acá lo mismo, pues apenas las media un tabique, por lo que juzgo que dando Dios salud a Su Excelencia y a Vuestra Señoría para que le ayude con una resolución firme, harán obedecer a los estorbadores que perturban y pervierten aun las más justas disposiciones, y quedará nombre inmortal de tal resolución y tendrá la Corte que agradecer para siempre este beneficio.

En Madrid quitan de noche las cortinas del tercer alto de las casas y las rejas bajas. Acá las más ventanas sólo tienen de vidrios y una cortina y no falta nada; en las calles en muchas de ellas para impedir no pasen coches cuando estorban, tienen cadenas y nadie las quita y en Madrid suelen llevarse las rejas.

Dios dé a Vuestra Señoría muchos años como deseo y mantenga en su mayor grandeza y lo mismo deseo a Su Excelencia. París, 26 de diciembre de 1751. Beso la mano de Vuestra Señoría, su más atento y seguro servidor,

Jaime Bort.

Señor Don Agustín Pablo de Ordeñana. 
Anexo 3: Carta de Jaime Bort a Zenón de Somodevilla y Bengoechea, marqués de la Ensenada, 7 de febrero de $1752^{29}$.

\author{
Excelentísimo Señor,
}

Por Don Joseph Aldecoa y Don Ventura Lloberas he sabido lo que Vuestra Excelencia me favorece, quienes han estado prontos a cumplir las órdenes de Vuestra Excelencia y generosamente han contribuido a consolarme en mis cuitas pasadas y al mismo tiempo socorrido con la mayor caridad, bastándoles para esto sólo el oír el nombre de Vuestra Excelencia. También han ayudado en el modo posible a que pudiese satisfacer mi curiosidad y encargo, aunque les ha sido algo difícil por lo recelosos que son nuestros aliados o envidiosos.

A los Padres de la Compañía que hay aquí españoles hicieron el encargo que me buscasen algún sujeto que pudiese contribuir a suministrarme las noticias que para cumplir mi encargo necesitaba, lo que hicieron liberales estos padres. Son el Padre Martínez, el Padre López y el Padre Marín, me dieron conocimiento con un tal Mr. Pedrañe, pensionario del Rey de España Mi Señor, hombre muy cabal y afecto a la nación, y con otro español americano hijo de español cuyas prendas son imponderables, las que perdonándome Vuestra Excelencia lo molesto me referiré más adelante. Se llama Don Pedro Dávila, el cual me introdujo con el conde de Caylus, sobrino del virrey de Valencia, hombre además de su nobleza sabido y retirado, y que sólo con haber sabido o entendido que yo traía recomendación de Vuestra Excelencia para que yo pudiese satisfacer mi curiosidad de las cosas tan grandes que hay en este país y a que transitaba por él, me acompañó y buscó un arquitecto para que me hiciese ver algunas obras y me informase cuanto desea ver y saber, en lo que estuvo pronto este caballero.

Me envió dos líos de papeles; el uno trataba de la iluminación, limpieza y empedrados; el otro de fuentes, conductos y egudes o alcantarillas. Saqué de ellos lo que conducía a mi encargo, de lo cual he remitido algunas copias al Marqués de Rafal y le he llenado de especies de este intento; también me ha ofrecido que vea yo en qué me puede servir para que logre saber lo que necesitase y que si se me ofrecen cartas de recomendación para Flandes, que me dará carta nueva (?).

Y volviendo a Don Pedro Dávila debo decir que es hombre en quien concurren las mayores prendas que en los más cultos se pueden encontrar. Permítame Vuestra Excelencia diga lo que siento, aunque sea un poco molesto. Es de edad como de treinta, galán, prudente, liberal, sabio, desinteresado y curioso. De lo que mis ojos he podido examinar y ver puedo decir que me faltan voces para ponderarlo, es el único sujeto que pudiera llenar el gusto delicado y noble de Vuestra Excelencia, y que si estuviera en mi mano se le presentaría a Vuestra Excelencia en pago de los favores que a Vuestra Excelencia debo y puedo recibir, que no es poco ponderar.

${ }^{29}$ AGS, Gracia y Justicia, leg. 998. 
Es universal en cuantas cosas puedan contribuir a lo racional de un hombre para ser de gusto. Es mucha su honradez. A esto corresponde los bienes que le acompañan porque sin ellos no podía haber juntado tantas cosas de tantas especies y todas selectísimas y de mucho valor, pues aquí entre los inteligentes le juzgan que le habrán costado un millón de reales. Con esto digo cuanto hay que decir de un hombre sin estados. Este sujeto prefiere el gusto a cuantos tesoros pudiera lograr con sus caudales en la América y creo despreciará cuanto el mundo ofrece de intereses con tal de no privarse de su inclinación. Es tan eficaz que tiene tres maestros para diferentes cosas que le cuestan todos los días nueve pesetas, cinco años que lleva esta tarea. Cuantas veces he estado en su casa he visto concurso de hombres sabios y nobles, y los más días se lo llevan a comer los primeros sujetos de París. Cuantas alhajas se venden en París selectas, primero van a su casa porque saben que es el único que las conoce y compra. Y si a Vuestra Excelencia se le ofreciese algún encargo, nadie podrá desempeñarle igualmente. Hoy me dijo se vendía un gabinete de los preciosos de París y que tuviera gran gusto que Vuestra Excelencia le mandara algo porque tiene grandes noticias del gusto y grandiosidad de Vuestra Excelencia.

Lleno de gozo estoy oyendo ponderarse en París las grandezas de Vuestra Excelencia, las que creo son sin igual. Ya veo Señor que mis ponderaciones se harán sospechosas de adulación, pero están tan lejos de serlo como yo estoy de Madrid. La capellanía que yo puedo lograr vacará muy presto porque de mis 62 al extremo falta poco. Yo me alegrara ser de 25; lo uno por lo natural que es en los hombres el vivir, y lo otro para poderles emplear en el servicio de Vuestra Excelencia complaciéndole y coadyuvando a sacar airoso a Vuestra Excelencia en sus grandes y nobles deseos, y a que se dilate su merecida fama a la mayor posteridad del tiempo por ser digno de eterna memoria cuan Vuestra Excelencia hace y bien hace.

Yo doy a Vuestra Excelencia infinitísimos agradecimientos por tanto como le merezco, y en particular al presente en que me hallo como ya Vuestra Excelencia sabe de cuanto a Vuestra Excelencia he ponderado. Si fuese menester los Padres de la Compañía dichos arriba informarán a Vuestra Excelencia de mi verdad. Vuestra Excelencia mande avisarme si tuviese algo que advertirme para que yo pueda complacerme, nada tengo en olvido ni omitiré de cuanto el Señor Don Agustín ${ }^{30}$ me tiene hecho cargo.

En acabando unos modelos que tengo entre manos que son la del gran reservoir, la máquina de la Samaritana ${ }^{31}$ y tres molinos, todo selecto, pasaré a Flandes en donde me aseguran que para esto son los únicos. En Gravelinas me ponderó Don Antonio Ulloa había mucho que ver y en muchas ciudades de aquellos parajes, de canales, inclusas y diques de donde se le siguen a estos países tantos intereses. Y a la vuelta si Vuestra Excelencia me permite pase a ver el canal de Languedoc y otro que se está actualmente trabajando, que son los únicos que ponderan ser de la mayor habilidad y arte, y el rodeo se puede reducir a 8 días más de camino.

\footnotetext{
${ }^{30}$ Agustín Pablo de Ordeñana.

${ }^{31}$ La Samaritaine
} 
Si Vuestra Excelencia me lo permite pasaré llevando conmigo un sobrino ${ }^{32}$ el cual se impone grandemente y me sirve de mucho alivio.

Aquí hay mucho que aprender y que ver, y por lo que mira a mi principal encargo aseguro a Vuestra Excelencia que no hallo dificultad alguna en la posibilidad, pues aquí ocurren mayores soluciones y sin embargo todas las casas tienen su comodidad y no les es de ninguna molestia.

Perdone Vuestra Excelencia lo molesto de mi causa, el afecto que a Vuestra Excelencia le profeso y los deseos de servirle lo han ocasionado. Dios quiera dilatar la vida de Vuestra Excelencia en honra suya y de la nación. Cuando veo Señor la enseñanza que acá tienen los que se crían, tantos hábiles en todas materias, me aflijo; qué escultura hay en las obras tan selectas, y no en nuestra España y en particular en la Corte, que las figuras se dan a destajo y a todos se les paga igualmente: buenos, malos y medianos, como que es facultad que ahí ni puede haber tantos iguales, lo que ocasiona que los selectos trabajan como iguales en el precio, y me parece que si los buenos no estuviesen mezclados con los medianos, desempañarán de otro modo sus obras. París, 7 de febrero de 1752. De Vuestra Excelencia su más obligado y afecto criado que sus manos besa,

Jaime Bort.

Ilustrísimo Señor Marqués de la Ensenada.

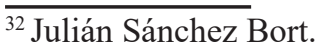

